\title{
THE PATHOGENESIS OF CASEIN CURDS IN THE STOOLS OF INFANTS *
}

\author{
ALFRED F. HESS, M.D. \\ NEW YORT
}

The subject of this paper is one that has interested pediatrists both in this country and in Germany for many years, but was brought forth anew for discussion a few year's ago. It is hardly necessary to review the history of investigations in this field. The articles have been many, and almost all have included a summary of the numerous investigations which have considered the problem of casein digestion. It is well known that although Biedert regarded protein indigestion as the main obstacle to successful artificial feeding of infants, this conception has been completely disavowed by his fellow countrymen. The question was not allowed, however, to slumber long, but was aroused again by Talbot, ${ }^{1}$ who described large, hard masses in the stool, which he termed casein curds, believing them to be composed mainly of the casein of the milk. Without enumerating the various writers who immediately took sides on this important question, it should be said that Meyer and Leopold, ${ }^{2}$ Southworth and Schloss, ${ }^{3}$ Ibrahim, ${ }^{4}$ Brennemann, ${ }^{5}$ and Courtney, ${ }^{6}$ published investigations for or against this partial retrogression to the old Biedert idea. As the result of intensive work on this subject; advance was rapidly made. Although no attempt will be made to detail the various experimental studies in this field, some few must be mentioned. In the first place, it was definitely shown by Talbot by means of various biologic tests that these curds do contain casein. It was, however, impossible by means of sensitive precipitin and hemolytic reactions to estimate how great a part of their substance the casein constituted. Another advance, shedding light on this subject, was the almost simultaneous reports of Ibrahim and of Brennemann showing that boiling the milk prevents the appearance of these masses in the stool. These studies, however, have not entirely elucidated the question. It is argued that these bean-like masses are only in part, perhaps in small part, composed of casein, and that although protein in nature, the main protein substance consists of

\footnotetext{
*From the Research Laboratory, Department of Health, New York City.

* Read before the New England Pediatric Society, March 1, 1913.

1. Talbot, F.: Arch. Pediat., December, 1909; June, 1910.

2. Meyer, L. F. and Leopold, J.: Arch. Pediat., October, 1909 ; February, 1910.

3. Southworth, T. and Schloss, O.: Arch. Pediat., April, 1909.

4. Ibrahim, J.: Monatsehr. f. Kinderǹ., 1911, x, 55.

5. Brennemann, J.: AM. Jour. Dis. CHILd., May, 1911.

6. Courtney, A. M.: AM. Jour. Dis. ChILd., January, 1912.
} 
intestinal secretion, which is mingled with the fat of the milk. Furthermore, they do not show whether the curds are formed in the stomach or in the intestine, or what leads to their formation, or how it is that in spite of the proteolytic enzymes, they pass through the entire intestinal tract undigested.

\section{PLACE OF FORMATION OF CURDS}

In the course of the care of a large number of infants in an asylum, this question was brought to notice, and has been a source of interest and consideration for the past year or more. It seemed almost certain that these masses in the stool are similar to those which are found in the stomach contents or in the vomitus of infants, but the difficulty lay, as is often the case, in finding a means of proving a palpable fact. In this connection, we wish to emphasize a point which we feel has not been granted sufficient importance, one which all investigators have noted, namely, that the interior of these masses is always white, although the exterior is stained brown or green by the stool. This fact would seem to afford very strong proof that these masses are formed in the stomach. For if they were formed in the small intestine beyond the point where the bile enters the duodenum, they undoubtedly would be mixed with bile, and their interior would be bile-stained. From this view-point, the bile may be regarded merely as a colored fluid which is injected into the upper duodenum, just beyond the pylorus. Nature provides in this way a most simple and convincing experiment, one which might well be devised were we to resort to animal experimentation for our purposes. Unformed substances which come from the stomach will certainly be mixed and tinged with the bile, whereas formed substances may remain unmixed and uncolored. If this be granted, it does not seem reasonable to dodge the conclusion that these masses must be formed before they enter the upper duodenum.

Another fact closely allied to the former and pointing in the same direction, is that the main fatty constituent of these masses is not fatty acid, but neutral fat; that the curd has not been acted on by lipase which enters at about the same point as the bile. Neither the bile nor the pancreatic fluid, therefore, has access to the interior of these masses.

A new method of approach to the question of the gastric or intestinal formation of these stool curds was afforded by the employment of the duodenal catheter. Last spring there was an infant, 3 months of age, in my hospital ward, who quite regularly passed casein curds. Its food consisted of half milk and half barley water with the addition of 5 per cent. cane-sugar; of this mixture, 6 ounces were given every four hours. For the purpose of preliminary experiment, this infant was fed solely on barley water for forty-eight hours, during which time the stools became brown and scanty, and the casein masses disappeared. It was then given 
by means of the duodenal catheter the same milk mixture which it had received before, and was fed very slowly five times in twenty-four hours. Duodenal alimentation was thus continued for forty-eight hours and the stools became yellow and larger, but contained no bean-shaped masses. Ordinary bottle feeding was again instituted, for the first two days merely barley water, and then the same milk mixture as originally given. Fortyeight hours after the milk was given by mouth, the casein masses reappeared in the stool. This would seem to show that these curds are formed in the stomach and disappear if the food is made to circumvent the stomach. The bile coloring test mentioned above, as well as the duodenal feeding test seem conclusive on this point.

\section{INHIBITING CURD FORMATION}

A series of experiments were undertaken with the view of inhibiting the formation of the casein masses. Many of these methods had been resorted to previously by others. For instance, boiling the milk (in these tests for five minutes) caused the masses to disappear. We were also able to confirm the results of others who found that 2 grains of sodium bicarbonate or of sodium citrate in an ounce of milk did away with their formation. Calcium chlorid, in 10 per cent. solution, added in the ratio of 1 to 20 to the milk was most effective, although not invariably so, in doing away with the formation of the curd masses. It was, however, not so easy to produce the curd at will; the most successful method was to give rennin at the time of each feeding. In many cases, but by no means in all, this was followed by the appearance of the large curds in the stool. Diluting whole milk with one-third barley water does not prevent or materially decrease the formation of the curds. We have had very many babies on this formula who passed casein curds, indeed, the most marked instance of curd masses which we have met with, occurred in the case of an infant who was receiving a mixture of this kind.

The question of the effect of heating the milk was entered on in somewhat greater detail. Milk was heated to varying temperature for successive days and it was found that when the milk was brought to about $170 \mathrm{~F}$. the curds almost always disappeared. They then occurred only occasionally and the appearance of the stools in this regard was quite different from that when milk was given that had been heated to a less high degree. We were especially anxious to determine the effect of pasteurization at $14 \mathrm{~F} \mathrm{~F}$. for forty-five minutes, because this is the type of pasteurization which is being employed by various dairies, and fully complies with the latest ordinance of the city of New York. Last year for this purpose some milk was pasteurized to this degree in our own apparatus, and this year milk was purchased which was thus pasteurized by the holding process at the creamery. It was found that pasteurization 
at this temperature did not do away to an appreciable extent with the formation of the curds in the stools; indeed, when recently in the course of experiments bearing on this question, we put fifteen infants on raw milk, we did not notice any increase in the formation of casein curds. In this connection, it may be added that an experiment was made to see the effect of freezing the milk. It was found that the curds appeared just the same, even after milk was given which had been frozen solid for a couple of hours. The substance, therefore, which goes to form these curds acts chemically like casein, which is changed in its power of coagulability by a temperature of about $170 \mathrm{~F}$.

\section{STUDY OF STOMACH CURDS}

Having assured ourselves that these curds were formed in the stomach, we directed our attention to the gastric digestion. With this end in view we used the stomach tube and evacuated the stomachs of many children, some of whom frequently passed curds, and others who were normal in this respect. However, we met with the same unsatisfactory experience as Tobler, who found that he was unable by this means completely to empty the stomach, and proved by means of the radiograph that some milk always remains behind. In our endeavors to overcome this diffculty, we used a large stomach tube; we irritated the pharynx with the tube or with the finger; we gave syrup of ipecac, and at times followed this by warm water given by the tube, but were unable by any of these means to incite vomiting at will. This was quite surprising in view of the marked tendency of infants to vomit at the least digestive or febrile disturbance. Indeed, we found that even when the infant vomits, the stomach does not always completely empty itself, as was shown by the fact that a second or even a third attack of romiting resulted in the renewed evacuation of large curds. So that at present it is impossible to carry out a satisfactory study of the gastric curds of infants. However, we examined the curds which we obtained by means of introducing the tube, as well as those from time to time vomited spontaneously. On comparing the size and the firmness of the curds of those infants who show casein masses in the stools with those who do not, it is evident that the former are larger and firmer. They are nevertheless always softer than the curds in the stool. But we have merely to shape these curds from the stomach, and to expose them for some hours to the air, to render them brown and at times almost indistinguishable from the bean-shaped curds of the stool. They are not so firm as the latter, probably because they have not undergone the continued pressure of the intestinal peristalsis. Apart from the difference in curd formation, nothing distinctive was noted in regard to the gastric contents of infants having casein

7. 'Tobler, L.: Ergeb d. inn. Med., 1908, i. 
masses in the stool. The stomach contents was not exceptionally acid at any stage of digestion. 'This is what we should expect when we consider that rennin is inhibited by a high degree of acidity. Free hydrochloric acid was occasionally met with.

It may be of interest to add a word concerning some attempts, althongh they proved negative, to increase the size or firmness of the gastric curd. Tobler ${ }^{7}$ states that the curd can be kept for long periods in the stomach if the infant is fed very frequently, so that the solid matter does not gain an opportunity of passing the pylorus. This idea was carried out on three children who were fed every hour with about three to four ounces of milk. Although they had at some previous time passed curds, during this three days' test no curds were found in the stool.

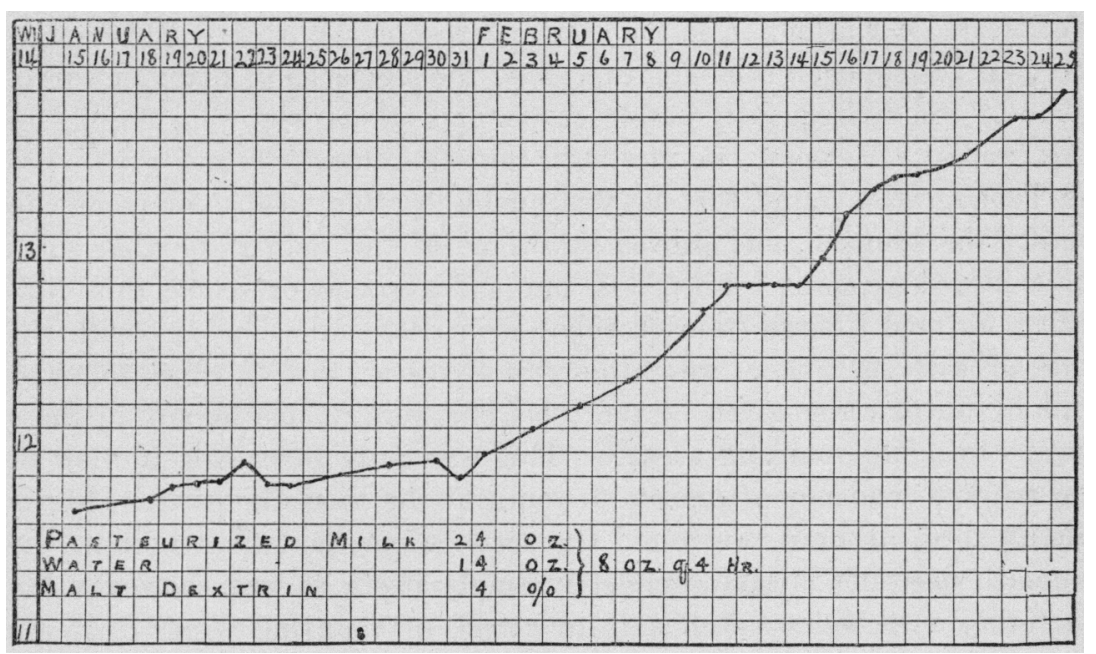

Chart showing steady gain in weight in spite of daily passage of large curds. I. L., aged 6 months.

Infants fed by the cup did not react differently from those fed by the bottle, nor did those fed rapidly through a large opening in the nipple, differ in their stools from those in whom the food was given slowly through a small aperture.

\section{STUDY OF DUODENAL CONTENTS}

So much for the formation of gastric curds. We next proceded to study the duodenal contents of these children. Many hundreds of examinations by means of the duodenal catheter had given us a definite idea of the curds normally found in the duodenum in infants. These curds are typical, to such an extent indeed, that they have been of aid to us in judging whether the tube has passed the pylorus; they may be regurgitated from the duodenum into the stomach. We have always noted them 
in our records as pyloric casts. They vary in length from about $1 / 8$ to $1 / 2$ an inch, and give the appearance of having been compressed through a narrow channel. They are quite what we should expect when we reflect on the radiographic pictures of milk in its passage through the pylorus. ${ }^{s}$ These curds afford us an opportunity of judging of the size and nature of the curd which normally enters the duodenum when an infant is fed on cow's milk. The duodenal contents of infants who passed the casein masses, especially those who passed these bodies constantly and in large numbers, was frequently found to be different. Although the diameter of the catheter prevented our obtaining a true picture of the size of the curds, it was noted that in these cases larger and coarser curds were aspirated, and that the lumen of the catheter became frequently plugged.

An examination of the trypsin was carried out in these cases. As the first step, the duodenal contents were aspirated from some infants who passed curds. It was found that the trypsin in these cases was normal, and was able to digest gelatin within twenty-four hours. It was just as potent as in infants who were not passing curds. Second, the curds from the stools were subjected to the action of the trypsin of the duodenal fluid of normal children, and it was found that even after they were kept under these conditions over twenty-four hours in the thermostat, the firm masses were not completely digested. In view of the fact that trypsin is one of the most powerful of the proteolytic ferments and readily digests casein, these tests show the importance of the density or compactness of a substance quite apart from its chemical constitution, in respect to its digestibility, and in particular of these casein masses. It should be considered; however, that these masses are probably much firmer when they are passed, than throughout their course in the small intestine.

A further experiment was instituted as a corrollary to these tests of trypsin. The curds of the stool were scraped, thoroughly washed with water, and then fed to some infants who passed curds, and to others who did not have them in the stools. Before feeding them, they were injected in the interior with fuchsin, so as to facilitate their recognition later. These curds were recovered in the stools from normal babies who for some time had not had casein masses in the stool. All of them were not found, but enough were recovered to show that these masses are incapable

8. 'These pyloric casts are frequently enveloped in a coat of mucus, which can be readily seen if the cast is floated on water, or in a fluid such as toluol which makes the enveloping substance more opaque. When this is done, we frequently find a long tail of mucoid substance attached to the curd. These bodies may be similar to the food strings noted in the duodenum by Cannon by means of the Huoroscope. 'They are not formed merely in the passage through the catheter, as they cannot be obtained from the milk within the stomach, and are frequently of a diameter smaller than the catheter. 
of being digested in the gastro-intestinal tract of the normal infant. Similar experiments with the gastric curds were undertaken, but thus far are not conclusive.

\section{OCCURRENCE OF CURDS AND EFFECT ON HEALTH}

Our series of investigations may be divided into two groups, both as regards time and method of approach. The first one taken a year ago consisted in noting throughout the asylum the various cases in which curds were found in the stool, and in keeping for months a daily record of these cases. This showed us that there were certain infants who passed these curds for long periods, although they seemed to be in perfect health, and no wise differing from others who were obtaining the same food and whose stools were normal.

More recently we have undertaken an experiment less broad, but more intensive in nature. We inspected the stools in a ward composed of sixteen infants, ten of whom were obtaining 40 ounces of $2 / 3$ milk with 5 per cent. sugar, and who varied in age from 6 months to a year, and six infants varying in age from 1 to 2 years, who were receiving a pint of milk, together with mixed diet. The milk had been pasteurized at $14 \%$ F. for forty-minutes. For a period of over a month, every stool was saved and inspected either by the house physician or by myself, and a record made as to its character and whether or not it contained casein masses. Vegetables were not given, as their coloring matter interfered with the examination of the stool. In the course of this month there was no child that did not at some time pass casein masses. Some passed them far more regularly than others; the younger group passed them more frequently than the older group. There was the same individuality noticed as had been remarked on last year; certain infants, independent of their well-being or of any clinical manifestation, had a peculiar tendency to pass bean-like masses in their stools. This tendency seemed to persist, for on examining the stools of the infants who passed curds so frequently last year, and who now are in the high-chair ward, it was found that many of them, an undue proportion, are still passing curds. The curds are not so large nor so hard in any instance as they were when the infant was younger. Incidentally, it may be of interest to note that in the course of these examinations of all the stools, it was most striking that certain infants have characteristic stools apart from the presence of curds, and that frequently the observer is able to designate the stool of a certain child by its appearance and odor, although the other children are on the same diet. It was also soon evident that it is impossible to draw a sharp distinction between casein and non-casein material, for there are gradations in the curds. Some, although small, soft, and easily broken up, are clearly, judging from their appearance, of the same constitution as the 
firmer and larger masses, and differ solely in having undergone partial digestion.

There is one more question which should be considered, namely, whether this disturbance is purely gastric in nature, or whether it is also dependent on some intestinal derangement. We have seen that in these cases there is no deficiency of trypsin. Howerer, a lack of erepsin, the other intestinal ferment which is able to digest casein, would also faror the non-digestion of these curds and lead to their passage in the stool. The same would be true of any condition which increased intestinal peristalsis, although the secretion of ferments was normal. It can be definitely stated that these casein masses are found not only in normal stools, but in the stools of infants which have been normal for many consecutive days. They do not, therefore, viewed from the clinical standpoint, indicate an intestinal disturbance, nor do they by mechanical irritation lead to intestinal trouble. However, although there is no parallelism in this regard, when we look over the notes of about one thousand stools of the group of sixteen infants who were continuously observed, it is clear that the curds are found more often in stools that are not completely digested, and at times when there is some faulty digestion, than when the intestinal functions appear normal. They are noted most often when an infant had three or more stools in the course of twenty-four hours, but were not infrequently present when there was but one or two stools in the course of the day. Judged by the various clinical criteria, they seem to indicate simply non-digestion of abnormally curded casein, and not a specific type of indigestion, ${ }^{9}$ for there may be a steady gain in weight and no signs of indigestion, no loss of appetite, no vomiting, no rise of temperature. It is significant in this regard that the infant which gained the most weight and with the greatest regularity during the month of observation, chanced to be the very one which had curds most regularly in the stools (Chart 1).

\section{CONCLUSIONS}

From what has been stated, it would seem certain that the large bean-like masses in the stool concerning which there has been such difference of opinion, are curds which contain casein, and are formed in the stomach. The fact that they show no bile coloring matter in their interior goes to prove that they are moulded before they reach the level of the duodenum where the bile is poured into the intestine; the

9. It was found that when 1 per cent. of powdered casein is added to the daily food of infants who pass these large curds, it does not result in the appearance in the stools of a greater number of the casein masses. If the disturbance were due simply to a lack of casein digestion or a casein indigestion, we should expect an increase of the bean-like masses. Viewed from the intestinal standpoint it is rather a casein-curd non-digestion. We cannot consider the digestive disturbance a "raw milk dyspepsia" as Ibrahim has suggested, as it occurs so frequently when pasteurized milk is given. 
additional fact that they disappear when the food is introduced by catheter directly into the duodenum, and reappear when it is once more given by mouth, must be accepted as strong evidence towards this conclusion. We wish to lay emphasis on the observation that certain infants are peculiar in their tendency to pass the curds with slight intermissions for months, whereas other infants similarly fed pass stools normal in this respect. This shows that in studying the pathogenesis of this condition we must take a clinical as well as a laboratory point of view, and must consider the individual infant and not merely the chemical factors which favor or hinder the coagulation of milk in the stomach. There are some infants who produce larger and firmer curds in their stomachs, due either to the amount of rennin which they secrete, or to the abnormal conditions under which the enzyme acts on the milk. These larger masses were found in the stomach and also in the duodenum of infants who passed casein curds in the stools. Ordinarily, the milk curd is pressed from the pyloric curd of the stomach into the duodenum in the form of slender, compact "food strings," which may be termed pyloric casts. In the cases with curds in the stools, the catheter showed the duodenum to contain larger masses.

The curds are always of gastric origin and their pathogenesis is always gastric. The intestines play merely a secondary rôle. From the intestinal standpoint the curds indicate merely the non-digestion of casein masses. The intestinal disturbance which at times accompanies the appearance of these masses in the stool, may be of gastric orgin, or of the same origin as the disturbed gastric function; it is not caused by the curds, nor is it the cause of the curd formation.

We cannot close without considering whether this clinical condition is harmful, and whether therefore, therapeutic measures should be taken to obviate the formation of these curds. Although a healthy infant may thrive in spite of the curds, we cannot infer that they may not sometimes lead to more serious disturbance. Furthermore, it is open to question whether foreign bodies of this size should be allowed to form and te traverse the intestinal tract. Diluting milk with barley water does not check their formation, nor does pasteurization to $147 \mathrm{~F}$. for forty-five minutes, a process which complies with the ordinances of the health departments of various cities. Pasteurization to 170 or $175 \mathrm{~F}$. causes the curds to disappear to a large extent, and therefore may be said to render the milk more digestible in these cases. We believe that the curds should not be allowed to persist, but should be checked, either by a high degree of pasteurization or by boiling the milk.

154 West Seventy-Second Street. 